\title{
Psychiatry
}

Editorial | Vol 1 Iss 1

\section{Signs that You are a Victim of Narcissistic Abuse}

\author{
Sam Vaknin \\ Department of Psychology, Southern Federal University, Rostov-on-Don, Russia \\ Correspondence should be addressed to Sam Vaknin, samvaknin@gmail.com
}

Received: October 22, 2020; Accepted: December 03, 2020; Published Date: November 192020

\begin{abstract}
In 1995, I coined the phrase "narcissistic abuse" to describe a type of all-pervasive and pernicious abuse that led to CPTSD in its victims. C-PTSD (Complex PTSD or complex trauma) has been proposed as a new mental health diagnosis by Dr. Judith Herman of Harvard University to account for the impact of extended periods of trauma and abuse.
\end{abstract}

\section{KEYWORDS}

Abuse; Love; Pathology; Addiction; Biochemistry; Brain; Mind; Emotions; Cognitions; Neuroscience; Hormones; Trauma; PTSD; C-PTSD.

\section{INTRODUCTION}

In 1995, I coined the phrase "narcissistic abuse" to describe a subtype of abusive behavior that was allpervasive (across multiple areas of life) and involved a plethora of behaviors and manipulative or coercive techniques. Narcissistic abuse differed from all other types of abuse in its range, sophistication, duration, versatility, and expresses and premeditated intention to negate and vitiate the victim's personal autonomy, agency, selfefficacy, and well-being.

The victims of narcissistic abuse appeared to present a clinical picture substantially different to victims of other, more pinpointed and goal-oriented types of abuse. They were more depressed and anxious, disoriented, aggressive (defiant reactance), dissociative, and trapped or hopeless owing to learned (intermittently reinforced or operant conditioned) helplessness. In short: they were in the throes of trauma bonding (Stockholm syndrome), a kind of cultish shared psychosis (folies a deux).

Repeated abuse has long lasting pernicious and traumatic effects such as panic attacks, hypervigilance, sleep disturbances, flashbacks (intrusive memories), suicidal ideation, and psychosomatic symptoms. The victims experience shame, depression, anxiety, embarrassment, guilt, humiliation, abandonment, and an enhanced sense of vulnerability.

C-PTSD (Complex PTSD) has been proposed as a new mental health diagnosis by Dr. Judith Herman of Harvard University to account for the impact of extended periods of trauma and abuse.

In "Stalking - An Overview of the Problem" [Can J Psychiatry 1998; 43:473-476], authors Karen M Abrams and Gail Erlick Robinson write:

Citation: Sam Vaknin, Signs that You are a Victim of Narcissistic Abuse: A Case Report. Psychiatry 1(1): 7-12. 
"Initially, there is often much denial by the victim. Over time, however, the stress begins to erode the victim's life and psychological brutalization results. Sometimes the victim develops an almost fatal resolve that, inevitably, one day she will be murdered. Victims, unable to live a normal life, describe feeling stripped of self-worth and dignity. Personal control and resources, psychosocial development, social support, premorbid personality traits, and the severity of the stress may all influence how the victim experiences and responds to it... Victims stalked by ex-lovers may experience additional guilt and lowered self-esteem for perceived poor judgement in their relationship choices. Many victims become isolated and deprived of support when employers or friends withdraw after also being subjected to harassment or are cut off by the victim in order to protect them. Other tangible consequences include financial losses from quitting jobs, moving, and buying expensive security equipment in an attempt to gain privacy. Changing homes and jobs results in both material losses and loss of self-respect."

Surprisingly, verbal, psychological, and emotional abuse has the same effects as the physical variety [Psychology Today, September/October 2000 issue, p. 24]. Abuse of all kinds also interferes with the victim's ability to work. Abrams and Robinson wrote this [in "Occupational Effects of Stalking", Can J Psychiatry 2002; 47:468-472]:

"...Being stalked by a former partner may affect a victim's ability to work in 3 ways. First, the stalking behaviours often interfere directly with the ability to get to work (for example, flattening tires or other methods of preventing leaving the home). Second, the workplace may become an unsafe location if the offender decides to appear. Third, the mental health effects of such trauma may result in forgetfulness, fatigue, lowered concentration, and disorganization. These factors may lead to the loss of employment, with accompanying loss of income, security, and status."
Still, it is hard to generalize. Victims are not a uniform lot. In some cultures, abuse is commonplace and accepted as a legitimate mode of communication, a sign of love and caring, and a boost to the abusers self-image. In such circumstances, the victim is likely to adopt the norms of society and avoid serious trauma.

Deliberate, cold-blooded, and premeditated torture has worse and longer-lasting effects than abuse meted out by the abuser in rage and loss of self-control. The existence of a loving and accepting social support network is another mitigating factor. Finally, the ability to express negative emotions safely and to cope with them constructively is crucial to healing.

Typically, by the time the abuse reaches critical and allpervasive proportions, the abuser had already, spider-like, isolated his victim from family, friends, and colleagues. She is catapulted into a nether land, cult-like setting where reality itself dissolves into a continuing nightmare.

When she emerges on the other end of this wormhole, the abused woman (or, more rarely, man) feels helpless, selfdoubting, worthless, stupid, and a guilty failure for having botched her relationship and "abandoned" her "family". In an effort to regain perspective and avoid embarrassment, the victim denies the abuse or minimizes it.

No wonder that survivors of abuse tend to be clinically depressed, neglect their health and personal appearance, and succumb to boredom, rage, and impatience. Many end up abusing prescription drugs or drinking or otherwise behaving recklessly.

Some victims even develop Post-Traumatic Stress Disorder (PTSD). Contrary to popular misconceptions, Post-Traumatic Stress Disorder (PTSD) and Acute Stress Disorder (or Reaction) are not typical responses to prolonged abuse. They are the outcomes of sudden exposure to severe or extreme stressors (stressful events). Yet, some victims whose life or body have been directly 
and unequivocally threatened by an abuser react by developing these syndromes. PTSD is, therefore, typically associated with the aftermath of physical and sexual abuse in both children and adults. This is why another mental health diagnosis, C-PTSD (Complex PTSD) has been proposed by Dr. Judith Herman of Harvard University to account for the impact of extended periods of trauma and abuse. It is described here:

\section{How victims are affected by abuse}

One's (or someone else's) looming death, violation, personal injury, or powerful pain are sufficient to provoke the behaviours, cognitions, and emotions that together are known as PTSD. Even learning about such mishaps may be enough to trigger massive anxiety responses.

The first phase of PTSD involves incapacitating and overwhelming fear. The victim feels like she has been thrust into a nightmare or a horror movie. She is rendered helpless by her own terror. She keeps re-living the experience through recurrent and intrusive visual and auditory hallucinations ("flashbacks") or dreams. In some flashbacks, the victim has completely lapsed into a dissociative state and physically re-enacts the event while being thoroughly oblivious to her whereabouts.

In an attempt to suppress this constant playback and the attendant exaggerated startle response (jumpiness), the victim tries to avoid all stimuli associated, however indirectly, with the traumatic event. Many develop fullscale phobias (agoraphobia, claustrophobia, fear of heights, aversion to specific animals, objects, modes of transportation, neighborhoods, buildings, occupations, weather, and so on).

Most PTSD victims are especially vulnerable on the anniversaries of their abuse. They try to avoid thoughts, feelings, conversations, activities, situations, or people who remind them of the traumatic occurrence ("triggers").
This constant hypervigilance and arousal, sleep disorders (mainly insomnia), the irritability ("short fuse"), and the inability to concentrate and complete even relatively simple tasks erode the victim's resilience. Utterly fatigued, most patients manifest protracted periods of numbness, automatism, and, in radical cases, near-catatonic posture. Response times to verbal cues increase dramatically. Awareness of the environment decreases, sometimes dangerously so. The victims are described by their nearest and dearest as "zombies", "machines", or "automata".

The victims appear to be sleepwalking, depressed, dysphoric, anhedonic (not interested in anything and find pleasure in nothing). They report feeling detached, emotionally absent, estranged, and alienated. Many victims say that their "life is over" and expect to have no career, family, or otherwise meaningful future.

The victim's family and friends complain that she is no longer capable of showing intimacy, tenderness, compassion, empathy, and of having sex (due to her posttraumatic "frigidity"). Many victims become paranoid, impulsive, reckless, and self-destructive. Others somatise their mental problems and complain of numerous physical ailments. They all feel guilty, shameful, humiliated, desperate, hopeless, and hostile.

PTSD need not appear immediately after the harrowing experience. It can and often is delayed by days or even months. It lasts more than one month (usually much longer). Sufferers of PTSD report subjective distress (the manifestations of PTSD are ego-dystonic). They're functioning in various settings job performance, grades at school, sociability deteriorates markedly.

The DSM-IV-TR (Diagnostic and Statistical Manual) criteria for diagnosing PTSD are far too restrictive. PTSD seems to also develop in the wake of verbal and emotional abuse and in the aftermath of drawing out traumatic situations (such a nasty divorce). Hopefully, the text will be adapted to reflect this sad reality. 


\section{Sundry observations on trauma and post-traumatic conditions}

Trauma imprints everything and everyone involved or present at the stressful event, however tangentially. Places, people, smells, sounds, circumstances, objects, dates, and categories of the above, all get "stamped" with the traumatic experience.

Trauma imprinting is at the core of PTSD (Post-traumatic Stress Disorder), CPTSD (Complex PTSD), and triggering. Triggers are places, people, smells, sounds, circumstances, dates, or objects that are reminiscent of the same classes of stressors involved in the original trauma and evoke them.

Many exposure and retraumatization therapies (including, most recently, the treatment modality that I developed, Cold Therapy) make use of trauma imprinting to generate new, less stressful and less panic- or anxiety-inducing associations between extant triggers and thus to induce integration of the haywire emotions involved in the primary situation.

Major traumas can lead to either of two opposing outcomes: regression into infantile behaviors and defenses - or a spurt of personal growth and maturation. It all depends on how the trauma is processed.

Faced with devastatingly hurtful, overwhelming, and dysregulated emotions, personalities with a low level of organization react to trauma with decompensation, reckless acting out, and even psychotic microepisodes. Major depression and suicidal ideation are common.

In an attempt to restore a sense of safety, the individual regresses to an earlier - familiar and predictable - phase of life and evokes parental imagoes and interjects to protect, comfort, soothe, and take over responsibilities.

In a way, the trauma victim's parents herself by splitting her mind into a benevolent, forgiving, unconditionally loving inner object (mother or father) and a wayward, defiant, independent, and rebellious child or teen who is largely oblivious to the consequences of her actions.

More balanced, emotionally regulated, and mature persons reframe the trauma by accommodating it in a rational, evidence-based (not fictitious or counterfactual) narrative. They modify their theories about the world and the way it operates. They set new boundaries and generate new values, beliefs, and rules of conduct (new schemas). They process their emotions fully and are thereby rendered more self-efficacy. In other words: they grow up, having leveraged their painful losses as an engine of positive development geared towards the attainment of favorable long-term results.

Abuse and attachment, trauma and bonding form parabolic relationships: up to the vertex (the low point of the parabola), one member of the pair (abuse, trauma) sustains and enhances the other (attachment, bonding). Beyond that point, the former weakens and undermines the latter. The exact location of the vertex depends on individual experience, personal history, personality, cultural and social mores, peer input, and expectations.

\section{To simplify}

Up to a point, people - men and women - are attracted to abusers. When the maltreatment reaches the traumatic vertex, the emotional reaction flips and the hitherto victims are repelled by the gratuitous cruelty and are, therefore, ejected and catapulted out of the dyad, couple, or bond.

This means that the good guys and decent women don't stand a chance in the sexual and relationship marketplace. They always amount to distant and unattractive second or rebound choices. Nice guys and solid, stable gals are there to pick up the pieces, relegated to the unglamorous role of the sanitation workers of lopsided romance. 
They are rarely anything more than pedestrian providers and co-parents or, if they luck out, intimate companions in between their spouses's extramarital affairs with other, more abusive and, therefore, more thrilling and appealing others.

Cold feet: The remorse that accompanies a- usually major- decision (like getting married or acquiring a home). It often leads to passive-aggressive, reckless, immoral, or destructive behaviors intended to undermine further action and reverse course.

The recipient of such mistreatment is traumatized: he feels rejected or abandoned or betrayed or cruelly and unjustly abused or damaged. Trust is shattered.

But cold feet have little to do with the target: the jilted fiancee or the dumped lover or the defaulted seller. Cold feet represent complex inner dynamics of avoidance, repetition compulsion, prior traumas, low self-esteem, a labile sense of self-worth and inadequacy, fear of the unknown, and emotional dysregulation (being overwhelmed).

However, if you keep attracting into your life people who get cold feet, there could be a problem with your selection criteria - or with you. It behooves you to look into why you keep choosing the wrong folks or what's in you gives them cold feet. "Triggering cascade" is when a seemingly minor trigger results in vastly disproportional trauma. Painful memories, replete with the attendant negative emotions, are walled behind mental barriers: combinations of dams and firewalls.

Sometimes even an innocuous mishap or a merely an unpleasant event rupture these defenses and decades of hurt are released in an avalanche that, at times, can be life threatening.

\section{Narcissists and psychopaths are dreamwreckers}

They are particularly adept at provoking triggering cascades by aggressively and contemptuously frustrating both individual and social expectations, cherished and lifesustaining hope, deeply held beliefs, and ingrained fantasies and values.

Their lack of empathy, innate, goal focused cruelty and ruthlessness, absent impulse control, and mind boggling recklessness create a whiplash of shock and disorientation coupled with agony and a pervasive feeling of being existentially negated. Intolerable angst is the inevitable outcome.

\section{REFERENCES}

1. Stormberg D, Roningstam E, Gunderson J, et al. (1998) Pathological Narcissism in Bipolar Disorder Patients. Journal of Personality Disorders 12: 179-185.

2. Roningstam E (1996) Pathological Narcissism and Narcissistic Personality Disorder in Axis I Disorders. Harvard Review of Psychiatry 3: 326-340.

3. Alford CF (1988) Narcissism Socrates, the Frankfurt School and Psychoanalytic Theory.

4. Fairbairn WRD (1954) An object-relations theory of the personality.

5. Freud S (1953) Three essays on the theory of sexuality (1905). In The standard edition of the complete psychological works of Sigmund Freud, volume VII (1901-1905): A case of hysteria, three essays on sexuality and other works. 123246.

6. Freud S. On Narcissism- Standard Edition. 14: 73-107.

7. Golomb E, Brazil A (1992) Trapped in the mirror: Adult children of narcissists in their struggle for self. 
http://www.tridhascholars.org | June-2021

8. Greenberg JR, Mitchell SA (1983) Object Relations in Psychoanalytic Theory. Cambridge, MA, Harvard University Press, USA.

9. Grunberger B (1979) Narcissism: Psychoanalytic Essays- New York, International Universities Press, USA.

10. https://www.abebooks.co.uk/book-search/title/personality-structure-human-interaction-developing/author/guntrip-harry/

11. Horowitz MJ (1975) Sliding meanings: A defense against threat in narcissistic personalities. International Journal of Psychoanalytic Psychotherapy 4: 167-180.

12. Jacobson E (1964) The self and the object world.

13. Kernberg OF (1975) Borderline conditions and pathological Narcism, New York.

14. Klein M (1964) The Writings of Melanie Klein. Roger Money-Kyrle (Ed.). 4 Vol.

15. Kohut H (1971) The analysis of the self, New York (International Universities Press).

16. Lasch C (1979) The Culture of Narcissism - New York, Warner Books.

17. Alexander L (1997) Narcissism: Denial of the True Self. Touchstone Book, New York.

18. Millon T, Davis RO (1995) Disorders of personality: DSM-IV and beyond. John Wiley \& Sons.

19. Millon T, Millon CM, Meagher SE, et al. (2012) Personality disorders in modern life. John Wiley \& Sons.

20. Ronningstam E (2000) Disorders of narcissism: Diagnostic, clinical, and empirical implications. Jason Aronson.

21. Ronningstam E (1996) Pathological narcissism and narcissistic personality disorder in Axis I disorders. Harvard Review of Psychiatry 3(6):326-340.

22. Rothstein A (1984) The Narcissistic pursuit of reflection - 2nd revised edn. - New York, International Universities Press, 1984

23. Schwartz L (1974) Narcissistic personality disorders - a clinical discussion. Journal of the American Psychoanalytic Association 22(2): 292-306.

24. Stern DN (2018) The interpersonal world of the infant: A view from psychoanalysis and developmental psychology. Routledge.

25. Stormberg D, Ronningstam E, Gunderson J, et al. (1998) Brief communication: pathological narcissism in bipolar disorder patients. Journal of Personality Disorders 12(2): 179-185.

26. Vaknin S (2007) Malignant self-love: Narcissism revisited ( $10^{\text {th }}$ Revised Impression).

27. Zweig P (1968). The heresy of self-love: A study of subversive individualism. Basic books. 